\title{
A resposta psicossocial de impotência em pacientes no pós-operatório de cirurgia cardíaca*
}

\author{
THE PSYCHOSOCIAL RESPONSE OF POWERLESSNESS ON POSTOPERATIVE CARDIAC SURGERY PATIENTS \\ LA RESPUESTA PSICO-SOCIAL DE IMPOTENCIA EN PACIENTES EN EL POSTOPERATORIO DE \\ CIRURGÍA CARDÍACA
}

\author{
Cristiane Giffoni Braga', Diná de Almeida Lopes Monteiro da Cruz²
}

\begin{abstract}
* Braga CG. A resposta psicossocial de impotência e o "locus de controle" de pacientes no pós-operatório de cirurgia cardíaca. [dissertação]. São Paulo (SP): Escola de Enfermagem da USP; 1999.

1 Enfermeira. Mestre em Fundamentos de Enfermagem pela Escola de Enfermagem da USP. Doutoranda da Escola de Enfermagem da USP. Professora da Disciplina Semiologia e Semiotécnica da Escola de Enfermagem Wenceslau Braz Itajubá-MG.

cristiane-gbraga@uol.com.br 2 Enfermeira. Professora Doutora Associada do Departamento de Enfermagem Médico-Cirúrgica da Escola de Enfermagem da USP. mtmllf@usp.br
\end{abstract}

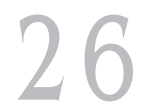

Rev Esc Enferm USP 2003; 37(1): 26-35

\begin{abstract}
RESUMO
Objetivos: descrever a impo-

tência no pós-operatório de

cirurgia cardíaca quanto a

freqüencia, intensidade,

características definidorase

comparar a impotencia em

pacientes em pós-operatório de

cirurgias de válvula (VAL) e de

coronária (RM). Método: a

presença de impotencia foi

definida pela análise de

entrevistas de 75 pacientes em

pós-operatório de cirurgia

cardíaca $(60 \%$ em pós-

operatório de RMe $40 \%$ de

VAL). Resultados: 44 (58,7\%)

pacientes apresentaram

impotência. Não houve

diferenças quanto a freqüencia

$(p=0,84)$ e intensidade

$(p=0,73)$ de impotência entre

os pós-operados de VAL e os

de RM. As características

definidoras mais freqüentes

nos pacientes com impotência

foram: "expressões verbais

relativas à falta de controle ou

de influências sobre uma

situação" (77,3\%), "dúvida

para planejar of futuro e

estabelecer objetivos"

(75,0\%), "expressão de

dúvida acerca do desempenho

de papéis" $(63,6 \%) e$

"expressões de insatisfação e

frustração pela inabilidade no

desempenho de tarefas elou

atividades pessoais" $(56,8 \%)$.
\end{abstract}

\section{PALAVRAS-CHAVE}

Impotência. Diagnóstico de enfermagem. Cuidados de enfermagem. Cirurgia cardiaca.

\author{
SUMMARY \\ Aims: to describe \\ powerlessness on \\ postoperative cardiac surgery \\ patients according to \\ frequency, intensity, defining \\ characteristics and to compare \\ powerlessness between \\ valvular surgery patients \\ (VAL) and coronary artery \\ bypass surgery patients \\ (CAB). Methods: \\ powerlessness was defined \\ through the analyses of \\ interviews of 75 patients $(60 \%$ \\ $V A L$ and $40 \%$ CAB). Results: \\ $58.7 \%$ patients presented \\ powerlessness. There were not \\ differences according to \\ powerlessness frequency \\ $(p=0.84)$ and intensity \\ $(p=0.73)$ between VAL and \\ $C A B$ patients. The defining \\ characteristics most frequent \\ on powerless patients were: \\ "verbal expressions of having \\ no control or influence over \\ situation" (77.3\%), "doubts \\ regarding planning future and \\ stating objectives" (75\%), \\ "expressions of doubt \\ regarding role performance" \\ (63.6\%), and "expressions of \\ dissatisfaction and frustration \\ over inability to perform \\ previous tasks and /or \\ activities" (56.8\%).
}

\section{KEYWORDS}

Powerlessness. Nursing diagnosis. Nursing care. Cardiac surgery.

\begin{abstract}
RESUMEN
Objetivos: describir la impotencia en el postoperatorio de cirurgía cardíaca cuánto a la frecuencia, intensidad, caracteristicas definidoras y comparar la impotencia en pacientes en postoperatorio de cirurgía de válvula (VAL) y de coronaria (RM). Metodos: La impotencia fue definida por el analises de entrevista de 75 pacientes $(60 \%$ RMy 40\%VAL). Resultados: $58,7 \%$ presentaron impotencia. No hulo diferencias cúanto a la frecuencia $(p=0,84) e$ intensidad $(p=0,73)$ de impotencia entre los postoperados de VAL y los de $R M$. Las caracteristicas definidoras más frecuentes en los pacientes com impotencia fueron: "expresiones verbales relacionadas com la falta de control o de influencias acerca de una situación” (77,3\%), "dudas para planear el futuro y establecer objetivos" (75,0\%) "expresión de duda acerca del desempenõ de roles" (63,6\%) y "expresiones de insatisfacción y frustración por la inabilidad en el desempeño de tareas y/o actividades personales"(56,8\%).
\end{abstract}

PALABRAS-CLAVE

Impotencia. Diagnóstico de enfermería. Atención de enfermería. Cirurgía cardíaca. 


\section{INTRODUÇÃO}

As doenças agudas e crônicas, geralmente, provocam sentimentos perturba-dores, bem como os tipos de tratamentos a elas direcionados. Esses sentimentos estão relacionados à forma de as pessoas atribuírem significados ao adoecer e ao tratamento. Assim, podemos dizer que as pessoas apresentam respostas ao adoecer. Estas podem, didaticamente, ser separadas em respostas orgânicas e em respostas psicossociais, embora não haja independência entre elas. As respostas orgânicas, mais visíveis, atentam-nos de forma significativa e assim as identificamos mais facilmente. Porém, as de ordem psicossocial parecemnos difíceis de caracterizar, pois envolvem fatores multidimen-sionais que se interrelacionam como, por exemplo, fatores culturais, características da personalidade, experiências passadas, fatores cognitivos e emocionais.

A impotência (powerlessness), como uma das possíveis respostas psicossociais ao adoecer, caracteriza uma necessidade de cuidado de enfermagem. O diagnóstico de impotência foi aceito para testes clínicos pela North American Nursing Diagnosis Association (NANDA) em 1982(1).

Um diagnóstico de enfermagem é um julgamento clínico das respostas do indivíduo, da família ou da comunidade aos processos vitais ou aos problemas de saúde atuais ou potenciais, os quais fornecem a base para a seleção das intervenções de enfermagem, para atingir resultados, pelos quais o enfermeiro é responsável ${ }^{(1-2)}$. A impotência foi definida pela NANDA como o estado no qual o indivíduo tem a percepção de que o que ele pode fazer não altera, significativamente, um resultado; a percepção da falta de controle sobre uma situação corrente, ou sobre um acontecimento imediato ${ }^{(1)}$.

Este artigo é relato de estudo sobre a impotência no pós-operatório de cirurgia cardíaca.

\section{REFERENCIAL TEÓRICO}

A impotência envolve a percepção por parte do paciente, de perda de controle $e^{(1,3)}$. Com base em observações de paciente com edema agudo de pulmão, White, Roberts $^{(3)}$ elaboraram um modelo em que o conceito de impotência tem quatro dimensões de perda de controle pessoal: fisiológico, cognitivo, ambiental e decisional. A Figura 1 representa essa proposta.

Descrevemos a seguir, as dimensões da impotência, conforme a proposta de White, Roberts $^{(3)}$. A perda de controle fisiológico refere-se aos sintomas físicos que muitas vezes impõem limites que a pessoa não pode controlar.

A perda de controle cognitivo está presente quando o paciente não consegue compreender as sensações físicas que experimenta; envolve a interpretação que o indivíduo faz e as conclusões a que chega a partir das informações obtidas pelos sentidos. O controle cognitivo refere-se tanto à sensação quanto à interpretação. $\mathrm{O}$ controle cognitivo sensorial consiste na percepção de ter poder
A resposta psicossocial de impotência em pacientes no pós-operatório de cirurgia cardíaca

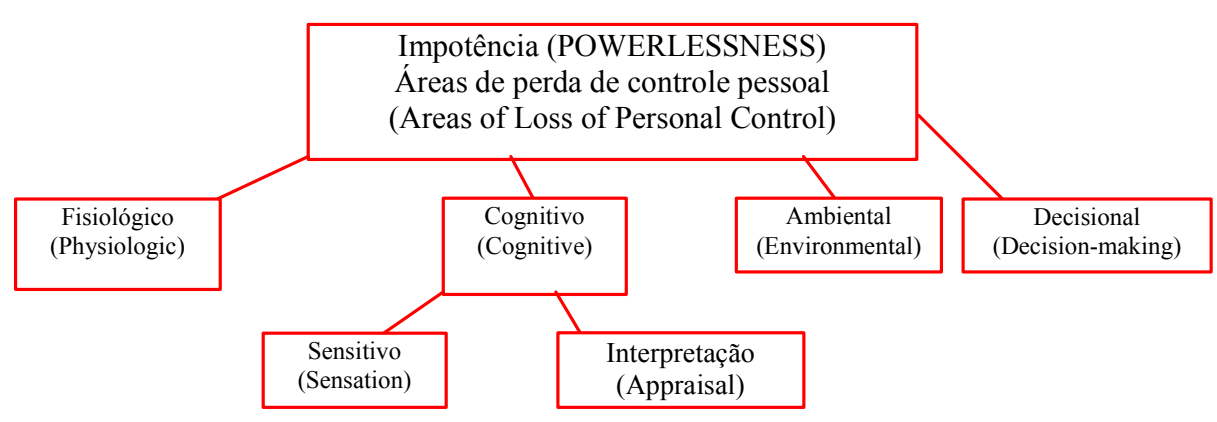

Fonte: White BS, Roberts SL. Powerles-sness and the pulmonary alveolar edema patient. Dimens Crit Care Nurs 1993; $12(3): 127-37$

Figura 1 - Modelo de Impotência mostrando as quatro áreas de controle pessoal 
Cristiane Giffoni Braga Diná de A.L.M. da Cruz

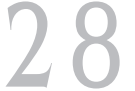

Rev Esc Enferm USP 2003; 37(1): 26-35 para criar uma imagem mental de que sensações esperar dos eventos que estão ocorrendo. A total falta de conhecimento de que sensações esperar origina sentimentos de impotência. $\mathrm{O}$ controle cognitivo referente à interpretação capacita o paciente a enfocar a atenção no evento ameaçador, a buscar pistas sobre um possível dano e a enfatizar a qualidade da experiência. Quando o paciente obtém informações sensoriais, ele as interpreta e faz uma avaliação subjetiva de seu controle sobre a situação.

A perda de controle ambiental é a percepção que a pessoa tem de não poder controlar um espaço físico que considera como seu território. O ambiente lhe é estranho e, se eventualmente conhecido, pode parecer-lhe hostil e impessoal. Percebendo-se, por imposição de outros ou por qualquer outra razão, incapaz de explorar o meio ou mudá-lo o paciente pode perceber-se impotente.

A perda de controle decisional ocorre quando a pessoa não tem mais o poder para tomar decisões sobre si e seu cuidado. O controle decisional depende da diversidade de opções de escolha em determinada situação e do "poder escolher".

Nas dimensões desse modelo de impotência está sempre presente a idéia de perda de controle. O controle é a percepção de poder pessoal sobre o meio e a situação. Refere-se à percepção pessoal de ter capacidade para regular, dirigir ou dominar uma situação ou evento dando à pessoa senso de independência e confiança $^{(3)}$. Dessa forma, as dimensões da impotência envolvem a idéia de poder ${ }^{(3)}$.

Poder é a habilidade ou capacidade, real ou potencial, para alcançar objetivos por processos interpessoais ${ }^{(4)}$. Hawks ${ }^{(4)}$ e Raatikainen ${ }^{(5)}$ estabelecem diferenças conceituais entre o poder para e o poder sobre $e^{(4-5)}$. O poder para refere-se à efetividade das ações, inclui a habilidade (competência) para alcançar objetivos, o significado pessoal de atingi-los e a capacidade para desempenhar papéis. É visto como um processo interpessoal que envolve participação de duas ou mais pessoas em que o objetivo e o significado para atingi-lo são mutuamente desenvolvidos e definidos.

O poder sobre é visto como um construto intrapessoal e significa a habilidade ou a capacidade para influenciar o comportamento e decisões dos outros, levando-os a obede- cer ou a conformar-se com a submissão. Envolve luta para dominar ou para recuperar-se de uma posição inferior para uma posição superior, tem uma força ou impacto direcionado. Abrange controle, competição, autoritarismo e liderança ${ }^{(4-5)}$.

Podemos inferir que a idéia de poder implícita no modelo de White, Roberts ${ }^{(3)}$ refere-se ao poder para conforme Hawks ${ }^{(4)}$ e Raatikainen $^{(5)}$ apresentaram. As dimensões da perda de controle na impotência referem-se a perda de poder para regular ou dirigir os limites impostos pelos sintomas físicos (fisiológico); perda de poder para regular ou dirigir a interpretação das informações sensoriais (cognitivo); perda de poder para regular o ambiente próximo (ambiental) e perda de poder para regular ou dirigir as próprias decisões (decisional).

Cada pessoa tende a manter o controle sobre os eventos em sua vida. A necessidade de controle pessoal não termina quando o paciente é hospitalizado; em vez disso, a necessidade pessoal de controle usualmente é intensificada em situações de dependência de cuidado ${ }^{(3)}$.

Usando os termos "poder" e "controle" como sinônimos Miller ${ }^{(6)}$ assume o pressuposto de que existem fontes de poder inerentes à própria pessoa. Categoriza-as da seguinte forma: vigor físico, resistência psicológica e suporte social, autoconceito positivo, energia, conhecimento e discernimento, motivação e sistema de crença ${ }^{(6)}$.

$\mathrm{O}$ vigor físico refere-se à capacidade individual para um ótimo funcionamento físico e à reserva física. Quando qualquer sistema corporal de uma pessoa é atingido por uma enfermidade seu poder individual para agir é menor. Assim, podemos afirmar que o estado do vigor físico influencia diretamente o senso de poder do paciente. A reserva física é a capacidade do corpo para manter o equilíbrio ao se confrontar com ameaças ou demandas extras.

A resistência psicológica refere-se a uma fonte de poder de recuperação (resiliency) presente, exclusivamente, no ser humano. A despeito das crises, das enfermidades e da incerteza do dia-a-dia, algumas pessoas são capazes de manter equilíbrio psicológico. Para alguns os eventos que poderiam ser vistos como ameaçadores são interpretados com significados positivos ou fortalecedores.

O suporte social refere-se à qualidade dos vínculos nos relacionamentos, à integração 
social, às oportunidades que a pessoa tem para estabelecer laços, à reconfirmação de seu valor, ao senso de aliança confiável e à percepção de receber apoio de pessoas nas quais deposita confiança ${ }^{(6)}$.

O autoconceito é o conjunto dos pensamentos e sentimentos do indivíduo sobre ele próprio $^{(6)}$. Os componentes do autoconceito incluem o "eu" físico (auto-imagem), o "eu" funcional (desempenho de papéis), o "eu" pessoal (eu moral; eu ideal; expectativas sobre si mesmo); e a auto-estima ${ }^{(6)}$.

Energia é a capacidade de um sistema para desempenhar um trabalho; energia potencial é a energia armazenada. Precisa haver equilíbrio entre o consumo e produção de energia que, no ser humano, pode ser obtida pelos nutrientes, água, repouso e motivação. A energia é consumida para recuperar ou corrigir estados físicos, para lidar (to cope) com as demandas da vida diária e com o estresse não usual. O desenvolvimento pela aprendizagem, pelo trabalho e pelo brinquedo também consome energia ${ }^{(6)}$.

O conhecimento é um "provedor estrutural" que diminui a incerteza ${ }^{(7)}$ e permite o desenvolvimento de um mapa cognitivo para interpretação dos eventos, admitindo às pessoas atribuir significados aos eventos relativos à saúde ${ }^{(6)}$. Dessa forma, o conhecimento e discernimento da pessoa sobre o que está acontecendo consigo mesma, permite que ela sinta maior controle da situação, constituindo-se em fonte de poder.

A teoria da motivação, baseada na competência e autodeterminação foi revisada por DECI apud Miller ${ }^{(6)}$. Essa teoria propõe desenvolver o senso de controle do doente sobre si e sobre o ambiente. A eficácia da teoria refere-se à capacidade do indivíduo de manipular o meio, não apenas para satisfazer suas necessidades básicas (por exemplo: comer, conforto), mas para sentir-se realizado, satisfeito, competente e autodeterminado ${ }^{(6)}$. A motivação é, portanto, uma fonte de poder.

O sistema de crenças abrange a crença em Deus para prover força e capacidade para lidar com o estresse, crença nos regimes terapêuticos, crença nos cuidadores e crença em si mesmo que é ter confiança nas próprias capacidades. Configura-se em fonte de $\operatorname{poder}^{(6)}$.

Quando essas fontes de poder estão íntegras a impotência não é um problema por- que o paciente desenvolve a percepção de maior controle sobre a situação ${ }^{(6)}$. O oposto da percepção de controle pessoal é a impotência ${ }^{(8)}$, definida pela NANDA como o estado no qual o indivíduo tem a percepção de que o que ele pode fazer não altera, significativamente, um resultado; a percepção da falta de controle de uma situação corrente, ou um acontecimento imediato ${ }^{(1)}$.

A impotência não é uma resposta dicotômica, mas é, antes de tudo, um continuum $^{(9)}$. Qualquer processo de doença, agudo ou crônico, pode predispor à impotência. A percepção de impotência é uma condição que pode afetar todas as pessoas através da vida ${ }^{(10-11)}$. As crianças hospitalizadas comumente experimentam a impotência no tocante ao ambiente hospitalar ${ }^{(9)}$. Já nos idosos, a vulnerabilidade para a impotência aumenta devido às freqüentes perdas que geralmente experimentam $^{(9)}$. Muitos idosos possuem poucas fontes de poder íntegras tais como resistência, força física e motivação para melhorar a saúde e a adesão aos regimes de tratamento ${ }^{(12)}$. Estressores psicológicos tais como a morte de um amado, aposentadoria, deslocamento e as mudanças fisiológicas que acompanham o envelhecer podem aumentar a vulnerabilidade a sentimentos de impotência. A impotência pode ocorrer também no indivíduo com doença aguda, especificamente durante as fases de acompanhamento diagnóstico, quando os sintomas são mais prevalentes, a doença é mais debilitante, o indivíduo não teve muitas experiências com doenças ou quando a avaliação diagnóstica é prolongada ou muito invasiva ${ }^{(3,12-14)}$.

Com a doença crônica que impõe um longo período de adaptação, há aumento do risco de sentimentos de impotência ${ }^{(6,15)}$. O paciente pode experimentar flutuações no estado de saúde com o início de deterioração, com os procedimentos diagnósticos e tratamentos invasivos, eventos que podem alterar a si e a seu estilo de vida.

Vários fatores contribuem para a percepção de impotência do paciente: o meio atual de cuidados de saúde, a tecnologia e linguagem pouco ou nada familiares, sua privacidade e necessidades muitas vezes ignoradas, assim como a remoção de seus objetos pessoais. $\mathrm{O}$ acesso ao paciente é limitado, a vigilância constante e o uso de equipamentos em seu território são freqüentes. Também as interações pessoais podem desencorajar o envolvimento do paciente no tratamento, re-
A resposta psicossocial de impotência em pacientes no pós-operatório de cirurgia cardíaca 
Cristiane Giffoni Braga Diná de A.L.M. da Cruz

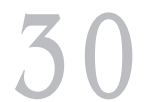

Rev Esc Enferm USP 2003; 37(1): 26-35 forçando fracassos pessoais prévios, o que predispõe ao senso de fragilidade e diminui o controle sobre $\mathrm{si}^{(12)}$

A impotência percebida pelo paciente guarda estreita relação com o ambiente de cuidados que pode favorecer ou, de certa forma, impor essa percepção ${ }^{(13)}$. Os cuidados de enfermagem são elementos importantes para que os pacientes desenvolvam maior ou menor percepção de controle das situações $^{(13)}$. A supervisão contínua que as enfermeiras realizam sobre os pacientes, levando-os a não assumir responsabilidades em seus próprios cuidados poderá provocar diminuição da auto-estima e sentimentos de impotência nesses pacientes ${ }^{(15-16)}$.

Os diagnósticos de enfermagem provêm os focos da ciência clínica da enfermagem ${ }^{(17)}$. Para ser competente em seu exercício profissional, a enfermeira deve ser hábil para decidir quais são as necessidades de cuidados daqueles de quem cuida. Se decidir sobre os cuidados necessários envolve discriminar as situações que demandam esses cuidados e se essa discriminação é entendida como uma atividade diagnóstica, então podemos aceitar o diagnóstico de enfermagem como um instrumento de trabalho da enfermeira, fundamental para o exercício competente da sua profissão ${ }^{(17)}$.

Entre as vantagens de nomear as interpretações dos dados de enfermagem, está a melhora efetiva da comunicação entre a equipe de enfermagem e com os outros. Classificar interpretações que são derivadas do conhecimento sobre os pacientes, constitui construir "mapas de território". Tais "mapas" guiam a enfermagem na promoção de serviços individualizados aos pacientes ${ }^{(18)}$.

Miller $^{(6,19)}$, com seus estudos sobre o diagnóstico de impotência, contribuiu significativamente para o conhecimento sobre essa percepção do paciente. Verificou que a falta de controle em uma situação de saúde conduz o paciente à apatia, à diminuição de sua interação, e à não participação nos cuidados ou nas tomadas de decisão ${ }^{(20-21)}$.

As enfermeiras estão em exposição freqüente a esse diagnóstico de enfermagem pelo fato de estarem em contato com pacientes que experimentam a percepção de falta de controle sobre uma situação atual ou sobre um acontecimento imediato, como na incerteza de um prognóstico e na promoção de sua saúde ${ }^{(11)}$. Mui- tas vezes, ao cuidarem desses pacientes inadvertidamente promovem a percepção de impotência pelo paciente. Comparada a outras disciplinas de que envolvem o cuidado ao paciente, a enfermagem deveria ser a disciplina com mais preparo e mais apropriada para aliviar ou evitar tal resposta ${ }^{(19)}$. Dessa forma, faz-se necessário explorar esse diagnóstico, supostamente freqüente nos pacientes.

Os pós-operatórios de cirurgia cardíaca geralmente representam situações transitórias de maior dependência dos pacientes, especialmente no período de internação. O cuidado de enfermagem deve suprir necessidades de ordem psicossocial, entre as quais figura a impotência. Desta forma os objetivos deste estudo foram: descrever a impotência no pós-operatório de cirurgia cardíaca quanto a freqüência, intensidade, características definidoras e comparar a impotência (freqüência e intensidade) em pacientes em pós-operatório de cirurgias de válvula e de coronária.

\section{CASUÍSTICA E MÉTODO}

O projeto desta pesquisa foi aprovado pela comissão de ética do hospital onde foi realizado e todos os doentes assinaram o termo de consentimento informado. O estudo foi realizado em clínicas de cirurgias cardíacas.

A amostra de conveniência foi de 75 pacientes, sendo 45 (60\%) em pós-operatório de revascularização do miocárido $(\mathrm{RM})$ e 30 (40\%) em pós-operatório para correção de disfunções valvares (VAL). Foram incluídos pacientes que atenderam aos seguintes critérios: estar no mínimo no quinto pós-opertório, visto que antes julgou-se cansativo para o doente; estar em condições de comunicação verbal; consentir em participar do estudo.

O instrumento para identificação das características definidoras da impotência na amostra foi elaborado especificamente para este estudo. Possíveis características definidoras foram levantadas na literatura e, depois de analisadas quanto a possíveis redundâncias, foram elaboradas suas definições operacionais. Essas definições operacionais nortearam a elaboração dos itens do instrumento utilizado para entrevistar os doentes e registrar suas respostas. A primeira parte do instrumento foi utilizada para o registro dos dados demográficos e da internação do paciente. A segunda parte constou de 30 pergun- 
tas. Treze perguntas previam resposta em escala tipo Likert, de 4 pontos, de forma que o doente pudesse responder a intensidade com que as características ocorriam com ele. Oito questões eram abertas e cinco eram de respostas tipo sim/não e especifique; quatro questões eram fechadas.

O conceito de impotência está relacionado à percepção de controle sobre as situações; nesse caso específico, sobre a situação de saúde. $\mathrm{O}$ instrumento elaborado continha várias perguntas sobre o "grau de controle" que o paciente considerava ter sobre determinada situação. Durante o teste piloto (com três doentes) observou-se que era possível o paciente ter interpretação errônea ou diversa sobre o que vinha a ser "controle" no contexto do estudo. Por isso elaborou-se um texto cujo objetivo era expressar para o paciente a idéia de controle sobre a qual se trataria na entrevista. A pesquisadora lia o texto antes da entrevista e o paciente que tivesse condições e assim o quisesse podia acompanhar a leitura em impresso a ele fornecido. Ao paciente era permitido perguntar e buscar esclarecimentos sobre o conceito, até que se sentisse satisfeito.

Para indicar se o paciente apresentava ou não a resposta de impotência, os dados do formulário de entrevista foram analisados pelas duas autoras, primeiro separadamente e, depois em conjunto de acordo com os procedimentos descritos por Braga ${ }^{(23)}$.

Com base no consenso entre as autoras na interpretação dos dados, a cada paciente foi atribuído um grau de impotência (0-sem impotência, 1-impotência leve, 2-impotência moderada, 3-impotência intensa). Além disso, dispunha-se também das informações sobre a presença ou não de cada característica definidora para cada paciente.

\section{RESULTADOS E DISCUSSÃO}

Quarenta e cinco (60\%) pacientes em pósoperatório de (RM) e 30 (40\%) em pós-operatório (VAL) compuseram a amostra de conveniência deste estudo. Dentre os 75 pacientes, $62,7 \%$ eram do sexo masculino; a idade média foi de 57,2 ( $\pm 12,5)$ anos; a escolaridade média de $6,4( \pm 4,6)$ anos e o tempo médio de pósoperatório à coleta dos dados de 7,5 dias.

Dos 75 pacientes, 44 (58,7\%) apresentaram algum grau de impotência. Podemos considerar que essa freqüência é importante, con- firmando, de certa forma, que a população de risco para se desenvolver a impotência é expressiva $^{(12)}$.

Campos $^{(22)}$, em estudo sobre cardíacos, salienta o modo de esses pacientes viverem a doença. Esse modo, apesar de ser específico para cada pessoa, emerge invariavelmente de um sentimento básico: ameaça de perda. Perda da vida, dos familiares, do poder. Pacientes cardíacos submetidos a tratamento medicamentoso sentem-se com certo controle da situação e acreditam que controlam a doença, mas, em tratamentos que requerem intervenções cirúrgicas, acesso invasivo, o paciente cardíaco encontra-se sob controle de outros, por exemplo, do médico, percebendo-se com falta de controle sobre a situação e acreditando que suas ações não afetarão os resultados ${ }^{(23)}$

Esse resultado deverá ser confirmado por outros estudos. O desenvolvimento de instrumento com propriedades psicométricas testadas para a avaliação da impotência poderá beneficiar o estudo da impotência em maiores amostras.

No presente estudo, além das perguntas fechadas, os pacientes responderam a oito questões abertas acerca de sua situação. Além disso, em um campo de notas, uma das autoras que entrevistou os doentes, registrou as manifestações não verbais que considerou relevantes no decorrer da entrevista para a posterior interpretação dos dados.

Quando a enfermeira obtém dados de seu paciente, não apenas os mais objetivos, mas também os subjetivos ela tem em mãos elementos fundamentais para conduzir o processo de avaliação, tornando rica a análise e, conseqüentemente, aperfeiçoando os resultados almejados ${ }^{(24)}$. Falas de 47 pacientes tiveram conteúdo explícito de sentimentos de falta de controle. Desses 47 pacientes, 44 tiveram o diagnóstico de impotência com base na interpretação do conjunto das suas respostas. Isso sugere que para avaliar a resposta de impotência é necessária uma exploração mais abrangente do que apenas uma expressão isolada. Por isso, um instrumento para avaliar a impotência em situações de saúde auxiliaria na melhor compreensão desse fenômeno.

A percepção, pelo paciente, de falta de controle sobre a situação e eventos de sua vida, pode caracterizar a resposta de impo-
A resposta psicossocia de impotência em pacientes no pós-operatório de cirurgia cardíaca 
Cristiane Giffoni Braga Diná de A.L.M. da Cruz tência. Essa resposta psicossocial - impotência - é um sentimento que todas as pessoas experimentam variando em grau e situação ${ }^{(9)}$.

Quanto ao grau da impotência, houve predominância de impotência de grau leve, estimada para $20(45,4 \%)$ pacientes e $9(20,4 \%)$ pacientes apresentaram impotência intensa. É possível que graus diferentes de impotência tenham distintas influências nas formas e resultados de os pacientes lidarem com suas enfermidades e processos de recuperação. Dada a relativa novidade do assunto, tais especulações poderão ser colocadas na forma de hipóteses testáveis somente à medida que o conceito "impotência" for desenvolvido, permitindo proposições teóricas adequadas.
A impotência como uma variável psicossocial tem atributos que não podem ser diretamente mensurados. Para afirmar clinicamente a sua presença esses atributos são inferidos. Como a impotência é indicada por diferentes atributos que necessitam ainda de estudos que os fortaleçam, apresentamos, a seguir, como as características definidoras, variáveis para a afirmação de impotência, se comportaram nos doentes com e sem impotência.

A Tabela 1, mostra as freqüências de características definidoras nos doentes com e sem impotência e os resultados do teste de Qui-quadrado ou Fisher sobre essas proporções.

Tabela 1 - Freqüências das características definidoras de impotência nos doentes com e sem impotência. São Paulo, 1998.

\begin{tabular}{|c|c|c|c|c|c|c|}
\hline & \multirow{3}{*}{ Características definidoras } & \multicolumn{5}{|c|}{ Impotência } \\
\hline & & \multicolumn{2}{|c|}{$\operatorname{Sim}(N=44)$} & \multicolumn{2}{|c|}{$\begin{array}{l}\text { Não } \\
(\mathrm{N}=31)\end{array}$} & \multirow{2}{*}{$p^{\dagger}$} \\
\hline & & $\mathbf{n}$ & $\%$ & $\mathbf{n}$ & $\%$ & \\
\hline 1. & $\begin{array}{l}\text { Expressões verbais relativas à falta de } \\
\text { controle ou de influências sobre uma }\end{array}$ & 34 & 77,3 & 4 & 12,9 & $0,00^{*}$ \\
\hline 2. & $\begin{array}{l}\text { situação. } \\
\text { Expressões verbais relativas à falta de }\end{array}$ & 11 & 25,0 & 1 & 3,2 & $0,01^{*}$ \\
\hline 3. & $\begin{array}{l}\text { controle ou de influência sobre um resultado. } \\
\text { Expressões verbais relativas à falta total de }\end{array}$ & 16 & 36,4 & 1 & 3,2 & $0,00^{*}$ \\
\hline 4. & $\begin{array}{l}\text { controle sobre o autocuidado. } \\
\text { Depressão causada pela deterioração física } \\
\text { que ocorre apesar de estar seguindo as }\end{array}$ & 12 & 27,3 & - & - & $0,00^{*}$ \\
\hline 5. & condutas determinadas. & 18 & 40,9 & 1 & 3,2 & $0,00^{*}$ \\
\hline 6. & Passividade. & 8 & 18,2 & - & - & $0,01^{*}$ \\
\hline 7. & Apatia. & 15 & 34,1 & 7 & 22,6 & 0,41 \\
\hline 8. & $\begin{array}{l}\text { Indiferença ao cuidado ou ao processo de } \\
\text { decisão quando há oportunidade. } \\
\text { Expressões de insatisfação e frustração pela } \\
\text { inabilidade no desempenho de tarefas e/ou }\end{array}$ & 25 & 56,8 & 11 & 35,5 & 0,11 \\
\hline 9. & $\begin{array}{l}\text { atividades pessoais. } \\
\text { Expressão de dúvida acerca do }\end{array}$ & 28 & 63,6 & 5 & 16,1 & $0,00^{*}$ \\
\hline 10. & $\begin{array}{l}\text { desempenho de papéis. } \\
\text { Relutância para expressar os verdadeiros } \\
\text { sentimentos demonstrando medo de } \\
\text { distanciamento das pessoas que }\end{array}$ & 11 & 25,0 & 5 & 16,1 & 0,52 \\
\hline 11. & $\begin{array}{l}\text { lhe prestam cuidado. } \\
\text { Inabilidade para buscar informações }\end{array}$ & 19 & 43,2 & 5 & 16,1 & $0,02^{*}$ \\
\hline 12. & $\begin{array}{l}\text { acerca do cuidado. } \\
\text { Dependência de outros, que pode resultar em }\end{array}$ & 20 & 45,4 & 9 & 29,0 & 0,23 \\
\hline 13. & $\begin{array}{l}\text { irritabilidade, ressentimento, raiva e culpa. } \\
\text { Falta de manutenção das práticas de }\end{array}$ & 14 & 31,8 & 4 & 12,9 & 0,10 \\
\hline 14. & $\begin{array}{l}\text { autocuidado quando desafiado. } \\
\text { Expressão de incerteza sobre os }\end{array}$ & 9 & 20,4 & - & - & $0,00^{*}$ \\
\hline 15. & resultados do tratamento. & 18 & 40,9 & - & - & $0,00^{*}$ \\
\hline 16. & $\begin{array}{l}\text { Ausência de observação de progressos } \\
\text { obtidos. }\end{array}$ & 33 & 75,0 & 9 & 29,0 & $0,00^{*}$ \\
\hline 17. & $\begin{array}{l}\text { Dúvida para planejar o futuro e } \\
\text { estabelecer objetivos. } \\
\text { Expressões de incerteza à respeito de níveis } \\
\text { flutuantes de energia. }\end{array}$ & 22 & 50,0 & 6 & 19,4 & $0,01^{*}$ \\
\hline
\end{tabular}


Quando existem características definidoras críticas, fica mais fácil para a enfermeira tomar as decisões para confirmar o diagnóstico $^{(25)}$. Características definidoras críticas são aquelas que devem estar presentes para confirmar o diagnóstico.

Miller ${ }^{(19,26)}$, que contribuiu significativamente para o estudo desse diagnóstico, relata como característica definidora crítica da impotência intensa a falta de controle sobre uma situação ou evento. Podemos constatar que essa característica definidora foi a mais freqüente $(34 / 77,3 \%)$ entre os doentes com impotência identificados neste estudo (44/ $100 \%$ ). Dos 31 pacientes não impotentes, houve $4(12,9 \%)$ pacientes com essa característica definidora. Apesar da freqüência não ter sido significante, a ocorrência dessa manifestação entre doentes sem o diagnóstico de impotência lança alguma dúvida quanto a ela ser mesmo uma característica definidora crítica ou quanto a utilidade clínica atribuída às características críticas dos diagnósticos.

Das 17 características estudadas 12 apresentaram freqüência estatisticamente maior nos pacientes com impotência, conforme era esperado. De qualquer forma esses resultados nos revelam que essas características são importantes na afirmação do diagnóstico de impotência na amostra estudada. Outros estudos são necessários para se confirmar a relevância ou não de cada possível característica definidora para afirmar a presença de impotência.

O diagnóstico de impotência (powerlessness) é uma resposta psicossocial, centrada em processos e manifestações comporta-mentais, cognitivas e emocionais e, talvez por isso mesmo, raramente identificada. As respostas psicossociais parecem ser muito freqüentes nos pacientes e constitui, sem dúvida, grande desafio à enfermagem ${ }^{(27-29)}$. "O foco da enfermagem ainda está fortemente centrado na área física, o que não é visto como um erro, mas sim, um descompasso entre o discurso e a prática. O primeiro prega uma assistência integral que inclui aspectos sociais, psicobiológicos e espirituais, mas a prática está centrada no biológico, nos diagnósticos médicos e na tecnologia" (27-28).

As Tabelas 2 e 3 mostram os resultados de comparação da impotência entre os pacientes submetidos a correções valvares (VAL) e os submetidos a revascularização do miocárdio (RM).

Tabela 2 - Freqüência da impotência segundo tipo de cirurgia (VAL e RM). São Paulo, 1998

\begin{tabular}{|c|c|c|c|c|c|}
\hline \multirow{3}{*}{ Impotência } & \multicolumn{5}{|c|}{ Tipo de cirurgia } \\
\hline & \multicolumn{2}{|c|}{ VAL } & \multicolumn{2}{|c|}{ RM } & \multirow{2}{*}{$p \dagger$} \\
\hline & $\mathbf{n}$ & $\%$ & $\mathbf{n}$ & $\%$ & \\
\hline Sim & 18 & 60,0 & 26 & 58,0 & \\
\hline Não & 12 & 40,0 & 19 & 42,0 & 0,848 \\
\hline Total & 30 & 100 & 45 & 100 & \\
\hline
\end{tabular}

†Teste Qui-quadrado

Tabela 3 - Intensidade da impotência segundo tipo de cirurgia (VAL e RM). São Paulo, 1998

\begin{tabular}{|c|c|c|c|c|c|}
\hline \multirow{3}{*}{$\begin{array}{c}\text { Grau de } \\
\text { impotência }\end{array}$} & \multicolumn{5}{|c|}{ Tipo de cirurgia } \\
\hline & \multicolumn{2}{|c|}{ VAL } & \multicolumn{2}{|c|}{ RM } & \multirow{2}{*}{$p^{\dagger}$} \\
\hline & $\mathbf{n}$ & $\%$ & $\mathbf{n}$ & $\%$ & \\
\hline Leve & 9 & 50,0 & 11 & 42,0 & \\
\hline Moderada & 5 & 28,0 & 10 & 39,0 & 0,763 \\
\hline Intensa & 4 & 22,0 & 5 & 19,0 & \\
\hline Total & 18 & 100 & 26 & 100 & \\
\hline
\end{tabular}

†Teste Qui-quadrado 
Cristiane Giffoni Braga Diná de A.L.M. da Cruz
Quanto a freqüência e intensidade da impotência, comparando os pacientes em pósoperatório de válvula (VAL) e de coronária (RM), verificamos que a proporção de impotentes nos dois grupos foi semelhante $(p=0,848)$. Com relação ao grau de impotência, também não detectamos diferenças $(p=0,763)$, ou seja, a distribuição dos pacientes com impotência entre os graus leve, moderado e intenso foi semelhante entre os pacientes de válvula e os de coronária.

As intervenções de enfermagem no pósoperatório de cirurgia cardíaca podem minimizar a impotência caso essa resposta seja adequadamente identificada. Destacamos a necessidade de estudos em que se controlem as influências de diferentes intervenções de enfermagem e de características de diferentes situações de saúde-doença na resposta psicossocial de impotência.

\section{CONCLUSÃO}

De 75 pacientes pós-operados de cirurgia de válvula e de coronárias, 44 (58,7\%) apresentaram impotência com predominância do grau leve. No total de pacientes com impotência, predominaram as características definidoras: "expressões verbais relativas à falta de controle ou de influências sobre uma situação" (77,3\%), "dúvida para planejar o futuro e estabelecer objetivos" (75,0\%), "expressão de dúvida acerca do desempenho de papéis" (63,6\%), "expressões de insatisfação e frustração pela inabilidade no desempenho de tarefas e/ou atividades pessoais" (56,8\%). As diferenças entre os pacientes submetidos a revascularização do miocárdio e os subme-

\section{REFERÊNCIAS}

(1) North American Nursing Diagnosis Association. Nursing diagnoses: definitions \& classification (1999-2000). Philadelphia: North American Nursing Diagnosis Association; 1999.

(2) Miers LJ. Nanda's definition of nursing diagnosis: a plea for conceptual clarity. Nurs Diagn 1992;2(1): 9-18.

(3) White BS, Roberts SL. Powerlessness and the pulmonary alveolar edema patient. Dimens Crit Care Nurs 1993; 12(3): 127-37.

(4) Hawks HJ. Power: a concept analysis. J Adv Nurs 1991; 16(6): 754-62. tidos a correções valvulares quanto a freqüência de impotência e quanto a intensidade da impotência não foram significantes.

Este estudo mostrou resultados relativos ao diagnóstico de enfermagem "powerlessness" - impotência - que esperamos que sirvam de base para futuros estudos, relacionando-os com o cuidar em enfermagem. O julgamento do diagnóstico foi feito mediante as experiências e conhecimentos das autoras com base nos critérios estabelecidos pela North American Nursing Diagnosis Association (NANDA) e na literatura especializada.

Estudos de validação desse diagnóstico que explorem os pesos de conjuntos de características definidoras para determinar sua influência na afirmação dos graus da impotência são necessários para acumular evidências quanto a importância de cada uma das características definidoras.

Dispor de conhecimento articulado sobre a identificação da impotência certamente proverá melhor compreensão dessa resposta para que possamos selecionar intervenções que aumentem o senso de controle do paciente $^{(8)}$.

Esperamos que esse estudo seja mais um desafio às enfermeiras na busca da concretização do cuidar numa perspectiva holística. A qualidade da assistência de enfermagem dependerá do olhar que lançarmos a nosso paciente; respeitando suas emoções, seu pensar, seu agir. Neste caminhar realmente poderemos falar como $\mathrm{Horta}^{(30)}$ : "enfermagem é gente que cuida de gente".
(5) Raatikainen R. Power or the lake of it in nursing care. J Adv Nurs 1994; 19(3): 424-32.

(6) Miller JF. Coping with chronic illness: overcoming powerlessness. $2^{\text {nd }} e d$. Philadelphia: F.A Davis; 1992 a.

(7) Mishel MH, Branden CJ. Finding meaning: antecedents of uncertainty in illness. Nurs Res 1988; 37(2): 98-103.

(8) Wetherbee LL. Powerlessness and the hospice client. Home Health Care Nurse 1995; 13(5): 37-41.

(9) Gordon M. Nursing Diagnosis: process and application. $3^{\text {th }}$ ed. St. Louis: Mosby; 1994. 
(10) Carpenito LJ. Nursing Diagnosis: application to clinical practice. $6^{\text {th }}$ ed. Philadelphia: JB Lippincott; 1995. Powerlessness; p.691-9.

(11) LambertVA, Lambert JrCE. Role theory and the concept of powerlessness. J.Psychosoc Nurs Mental Health Serv 1981; 19(9):11-4.

(12) Kubsch S, Wichowski HC. Restoring power through nursing intervention. Nurs Diag 1997; 8(1): 7-15.

(13) Mcfarland GK, Mcfarlane EA. Nursing diagnosis \& interventions: planning for patients care. St. Louis: Mosby; 1989. Powerlessness; p.621-9.

(14) Boeing MH, Mongera CO. Powerlessness in critical care patients. Dimens Crit Care Nurs 1989; 8(5): 274-9.

(15) Benjamin D. Powerlessness in chronic illness. Prairie Rose 1996; 65(4): 9a-10a .

(16) Arakelian M. An assessment and nursing application of the concept of locus of control. In: Ans-Advances in nursing science. Nursing theories and models. Aspen: Aspen Systems $1980 ;$ p. $25-42$.

(17) Gordon M, Sweeney MA. Methodological problems and issues in identifying and standardizing nursing diagnosis. Adv Nurs Sci 1979; 2(1):1-15.

(18) Cruz DALM. Diagnóstico de enfermagem: qual a abordagem no novo currículo. In: Guedes MVC, Araújo TL, organizadores. O uso do diagnóstico na prática da enfermagem. Brasília: ABEn; 1997. p.100-5. (Série Didática: enfermagem no SUS).

(19) Lunney M, Beverly AK, Kiss M, Murphy P. Accuracy of nurses'diagnoses of psychosocial responses. Nurs Diagn 1997; 8(4):157-66.

(20) Miller JF. Development and validation of a diagnostic label: powerlessness. In: Kim MJ, Mcfarland GK, Mcfarlane AM, editores. Classification of nursing diagnosis: proceeding of the fifth national conference. St. Louis: Mosby; 1984.
(21) Dunn JD. Powerlessness regarding health service barriers: construction na instrument. Nurs Diagn 1998; 9(4):136-43.

(22) Campos EP. Aspectos psicossomáticos em cardiologia. In: Mello FJ. Psicossomática hoje. Porto Alegre: Artes Médicas; 1992. cap.22, p.234-63.

(23) Braga CG. A resposta psicossocial de impotência e o "locus de controle" de pacientes no pós-operatório de cirurgia cardíaca. [dissertação] São Paulo (SP): Escola de Enfermagem da USP; 1999.

(24) Helgeson VS. Moderators of the relation between perceived control and adjustment to chronic illness. J Pers Soc Psychol Am Psychol Assoc 1992; 63(4): 656-66.

(25) Riccio GMG. Validação de um instrumento de levantamento de dados para formulação dos diagnósticos de enfermagem. Rev Soc Cardio Estado São Paulo 1995; 5 (3 Suppl A): 1-16.

(26) North American Nursing Diagnosis Association. Nursing diagnoses: definitions \& classification (1997-1998). Philadelphia: North American Nursing Diagnosis Association; 1996.

(27) Miller JF. Coping with chronic illness: overcoming powerlessness. $2^{\text {nd }}$ ed. Philadelphia: F.A .Davis 1992b.

(28) Maria VLR Elaboração de diagnóstico de enfermagem do paciente coronariano em estado crítico. [tese]. São Paulo (SP): Escola de Enfermagem da USP; 1997.

(29) Carvalho EC, Coler MS. Diagnosis of the human response pattern, communicating: a proposal for revision. Nurs Diagn 1995; 6(4):155-60.

(30) Horta WA. Gente que cuida de gente (editorial). Rev Enf Novas Dimens 1976; 4(4): iii.
A resposta psicossocial de impotência em pacientes no pós-operatório de cirurgia cardíaca 